\title{
Interest rates and inflation: What are the links?
}

\author{
Malcolm Sawyer*
}

The purpose is to examine some of the links in the chain which is said to run from the rate of interest to the rate of inflation. It is argued that that there is a tendency to slip from arguments which that the rate of interest is related to the price level to suggesting that the rate of interest is related to the rate of inflation. The neo-Wicksellian approach is examined and found to support more the view that the rate of interest impacts the level of prices rather than the rate of inflation. It is also argued that the route through the exchange rate does not support the view that higher interest rates will dampen down inflation (though it may lower prices relative to what they would have been). It is further argued that the link from the level of economic activity to the rate of inflation is theoretically dubious. In the last section it is briefly indicated that there is a lack of empirical support for any strong link from interest rate to inflation.

$J E L$ classifications: $E_{31}, E_{40}, E_{43}, E_{52}$

Keywords: interest rates, inflation, monetary policy

\section{Monetary policy and the control of inflation}

The use of interest rates as the policy instrument for the control of inflation has become a central feature of macroeconomic policy in many countries over the past two decades. Until recently it had appeared to be relatively successful in that inflation in most industrialised countries has been low, though there are clearly alternative explanations for this low inflation such as the downward pressure of prices coming from the growth of low cost produc-

* University of Leeds. I am grateful to Philip Arestis and Giuseppe Fontana for comments on an earlier draft of this paper, and for extensive discussions on the topics covered in this paper over a long time.

Correspondence Address:

University of Leeds, Economics Division, Leeds University Business School, University of Leeds, Leeds LS2 9JT, UK, e-mail: mcs@lubs.leeds.ac.uk.

Received 07 October 2008, accepted I2 February 2009

(C) INTERVENTION 6 (I), 2009, 8I-96 
tion in a number of Asian countries. The formal system of inflation targeting was often introduced after inflation had been reduced to a low level (following the much higher levels in the I970s and I980s) rather than being the policy instrument which brought about lower inflation. The general rise in inflation in 2008 around the world, the cost-push nature of this rise in prices, and the problems of operating a monetary policy in the face of a financial crisis have raised questions on the use of monetary policy (in the form of interest rate changes) to target inflation. In this paper we address just one aspect of the use of monetary policy in an inflation targeting framework, namely what are the relationships between the interest rate and the rate of inflation, with a main focus on the theoretical arguments and then with some reference to the empirical evidence.

When the term sthe rate of interest is used in this paper without any qualifier it refers to the key policy rate of interest set by the Central Bank. It is implicitly assumed that the general level of interest rates will follow from this policy rate of interest. This is not to say that other interest rates respond immediately and on a one-for-one basis with a change in the policy interest rate, and indeed the looseness of the links between general interest rates and the policy interest rate is a further problem for the effectiveness of monetary policy. Further, it will generally be the long-term rate of interest which is relevant for decisions such as those on investment and the degree to which the Central Bank's decisions on policy interest rate influence the long-term rate of interest is also relevant. However, in this paper we do not directly consider these aspects, but would generally regard them as undermining the strength of any links between the rate of interest and the rate of inflation.

The policy rate of interest is set in nominal terms, and any translation into a real rate of interest is undertaken as nominal rate minus expected rate of inflation. The actual measurement of expected rate of inflation can be difficult in a variety of ways, not least that economic agents differ in the expectations which they hold. The determination and measurement of expected inflation lies outside this paper, and here the notion of expected inflation is treated as unproblematic. Further, in this paper we do not need to specify how expectations are generated, and specifically there is no presumption made that expectations are $>$ rationalı. There is considerable discussion in what follows on a `natural rate of interest`, which we take to be a rate of interest expressed in real terms, though whether such a rate of interest in any sense exists is one of the questions to be explored.

Why has monetary policy in the form of interest rates been so closely associated with the targeting of inflation? Monetary policy became closely associated with control of inflation in the hey-day of monetarism in the early I980s when monetary policy itself was associated with attempts to control (or at least target) the money supply (however that was defined, which, of course, was one of the significant question marks over that policy). Monetarism in the form of control of the money supply has long been discarded in the face of difficulties of ensuring that the money supply grew at the targeted rate. But other key elements associated with monetarism such as the `natural rate of unemployment which has to be attained to prevent inflation rising and the dominance of the supply-side remain central to mainstream macroeconomic analysis as seen in the snew consensus in macroeconomicsı. 
Monetary policy has in practice always included the setting of some key policy interest rate, sometimes accompanied by credit controls and sometimes with seeking to target the money supply. But in the present setting, decisions on the policy rate of interest are generally taken to influence the level of demand, and monetary policy can at most only affect demand inflation (and not cost inflation). Even for demand inflation there are likely to be more effective ways of influencing the level of demand, and thereby inflation than the use of interest rates.

Another line of argument which has often been advanced for the use of monetary policy as the policy instrument for the control of inflation is that the setting of interest rates can be placed in the hands of an sindependent ‘ Central Bank. Central Bankers have been viewed as uniquely able to influence the level of demand without falling to the temptation to raise demand at inappropriate times, to be more committed to low inflation and to avoid the problems of time inconsistency ${ }^{I}$. The notion that the Central Bank has, or can acquire, credibility in terms of its commitment to the control of inflation, and that it is the Central Bank alone (the sconservativer central bankers argument) that has this credibility with respect to the control of inflation. The reasoning here becomes not so much that variations in the rate of interest rate will influence inflation, but rather that the expectations of low inflation will be reinforced and that itself will maintain low inflation.

In the snew consensus in macroeconomics (NCM) approach, (see Meyer 200I, for an introduction, Woodford 2003, for very detailed elaboration albeit using the term neo-Wicksellian, the Bank of England 2005, for a model along NCM lines in the context of building a macro-economic model, and Arestis/Sawyer 2008a for a critique), interest rate policy is viewed as influencing the level of economic activity which in turn can influence the rate of inflation. The rate of interest becomes the sole policy instrument and inflation the main (and often sole) policy objective. The instrument of the policy interest rate can be adjusted frequently (with decisions on interest rate being taken of the order of monthly), and there is in effect an attempt at ultra-fine tuning.

In this paper we seek to explore the links running from the level of the policy interest rate to the rate of inflation. This is undertaken in four stages. In the next section we examine the links coming from the (neo-) Wicksellian tradition. In Section 3 we briefly review the links which run through asset prices and the exchange rate, and in Section 4 we consider the second stage in the link running from interest rate to level of demand to rate of inflation, that is the Phillips' curve. In each of these stages there are two questions in which we are particularly interested: first, does the level of interest rates influence the rate of change of prices (rather than the level of prices), and second is the linkage positive or negative. Finally in Section 5 we briefly mention some empirical considerations and Section 6 concludes.

I A few such as Leith and Wren-Lewis (2005) have made proposals for a Fiscal Policy Committee which could, in effect, act in a similar manner but using fiscal policy, see also Taylor (2000). 


\section{Interest rates, the price level and the rate of inflation}

Monetarist theory had the feature that the rate of growth of the money supply sets the rate of inflation - that is the rate of change on the money supply was related to the rate of change of prices. The monetarist story regarded the direction of causation running from money to prices; the (post Keynesian) endogenous money supply approach would essentially reverse the direction of causation but still expect some correlation between the rate of change of the stock of money and that of prices.

The conventional argument was that the monetary authorities can control the stock of money or the policy rate of interest but not both. It is significant that it is the level of the stock of money, which is being related to the level of the policy interest rate. The post Keynesian approach would challenge that by arguing that the policy instrument has to be the rate of interest since the stock of money should be treated as an endogenous variable and thus not within the grip of the central bank.

The question we pose is how does the move, from relating the rate of change of money to the rate of change of prices, to relating the level of the interest rate to that rate of change of prices, occur. It is more usual in economic theorising to relate a level of one variable to the level of other variables, often followed by comparative static comparison of two equilibrium positions such that change in one variable is then related to change in other variables.

In any particular time period when there are factors leading to a different price level (as compared with the previous period), then there will be a calculated rate of inflation (which could be negative) for the period concerned. But should that be regarded as inflationary in the sense of a persistent rise in prices rather than a one-off increase in the price level? There are (at least) two ways in which a higher price level in one period could be regarded as inflationary rather than as a price adjustment. The first would arise when a higher price level did not involve all prices being higher to the same degree and hence involves some changes in relative prices (prices here broadly defined to include wages and imported prices). To the degree to which those whose relative price has diminished seek to restore their position in a subsequent period a round of inflation may be involved. The second would come through changes in expectations with regard to future prices and inflation. If the experience of higher prices in the present period is interpreted as experience of inflation, then expectations on future inflation may well adjust upwards to reflect that.

Wicksell wrote, with regard to a figure in his text with wholesale prices in Hamburg and England, and rate of interest in the central banks and on the open market in Berlin and London, that

wit must be admitted that if it is possible to discover any connection between them at all, it is that a high rate of interest is associated with high commodity prices and a low rate of interest with low commodity prices, rather than the other way round. Faithful to the principle we established earlier, however, we are not going to let ourselves be put out by this circumstance but, for the time being, we shall test the theory itself on grounds of logic« (Wicksell 1958: 78). 
This quote clearly refers to a positive relationship between rate of interest and the level of prices, now often referred to as Gibson's paradox.

Wicksell was, though, concerned with a cumulative process in which a low (high) rate of interest would lead to higher (lower) prices; low or high is to be judged by the market interest rate being below or above the `natural rate ( or `normal rates) of interest (to be further discussed below). He wrote,

"We consequently arrive at the following general principle: At any moment and in any economic situation there is always a certain rate of interest, at which the exchange value of money and the general level of commodity prices have no tendency to change. This can be called the normal rate of interest; its level is determined by the current natural rate of interest, the real return on capital in production, and must rise or fall with this. If the rate of interest on money deviates downwards, be it ever so little, from this normal level prices will, as long as the deviation lasts, rise continuously; if it deviates upwards, they will fall indefinitely in the same way." (Wicksell I958: $82-83$ )

Whilst in this passage Wicksell could be viewed as talking about a continuously rising price level (inflation), the snatural rater of interest is viewed as consistent with a constant price level. However, it is the price level which rises (or falls) continuously. In the current representations (that is the expectations augmented Phillips' curve) the snatural rate of interest is viewed as consistent with constant inflation, and deviations from the natural rate would produce rising (or falling) inflation. Wicksell's version contained a $>$ knife edge property in that any small divergence between money rate of interest and the snatural rate would lead to a continuously rising (or falling) price level. It should also be noted that Wicksell views the snatural rate of interest as subject to continual change with the money rate of interest tending to be sticky.

In Wicksell's approach, the snatural rate of interest is consistent with a constant price level, and any deviation of the market rate from the natural rate leads to rising or falling prices. Thus, the snatural rate of interest is not consistent with any constant rate of inflation, other than zero, and in particular not consistent with say a two per cent target. In the example which Wicksell gave a deviation of the market rate from the snatural rate leads to a rise in prices, which then repeats itself in subsequent periods so long as that deviation is maintained. The suggestion is that the degree of change in the price level will be repeated so long as the differential between the 'natural rate and the market rate is maintained.

In the context of the snew consensus in macroeconomics` models (cf. Arestis/Sawyer 2008a), it can be readily argued that any equilibrium or `natural rate of interest (defined there to correspond to constant inflation) would at most be defined for a specified level of the fiscal stance, world demand and set of ranimal spirits influencing investment. As these factors vary so will any >natural rate of interest . The Wicksellian approach specifies at most that a market rate of interest above the nnatural rate would lead to lower prices (and perhaps lower inflation, as explored further below), but if the snatural rate is continually var- 
ying any relationship between the market rate of interest and the price level (or the rate of inflation) will be obscured.

The neo-Wicksellian approach also seems to suggest that there is a continuum of 'natural ratesı. Woodford concludes that

"the model [developed] implies that for policy rules of these types [Taylor-type], equilibrium inflation depends solely upon the path of the gap between the natural rate of interest $[\ldots]$ and the intercept term [...] indicating the tightness of central-bank policy« (Woodford 2003: 277).

The intercept term corresponds to the Central Bank rate which would be set if inflation was on target, output gap zero (and the difference between lagged interest rate and lagged constant term also zero).

"Variations in the rate of inflation depend upon the interaction between the real factors that determine the natural rate of interest, on the one hand, and the way in which the central bank adjusts short-term nominal interest rates, on the other. Inflation will be stable insofar as the stance of monetary policy is varied to keep up with the exogenous variations in the natural rate of interest that occur as a result of real disturbances and not varied otherwise; it will be variable insofar as either factor varies other than in perfect tandem with the other.« (ibid.)

In Woodford (2003) a whole (and long) chapter is devoted to "price-level determinants under interest rate rules" (emphasis added) and in part this can be seen as seeking to counter the argument of Sargent and Wallace (1975) that interest rate rules do not lead to a determinant price level. The significant point to note here is that the discussion refers to the determination of price level based on an interest rate rule. Woodford (2003: 84-85) argues that it is current and expected future real rates of return and of current and expected future monetary policy rules which matter for the equilibrium price level. But he concludes that the implications of his analysis are

"reminiscent of Wicksell's prescriptions. First of all, suppose that the target price level $[\ldots]$ is constant $[\ldots]$ then monetary policy achieves the constant price level $[\ldots]$ if and only if $v_{t}$ [constant term in a monetary policy rule] $=\hat{r}_{t}$ ['natural rate of interest] at all times. Failure of policy to track such variations in the natural rate with sufficient accuracy was, in Wicksell's account, the primary explanation for price-level instability« (Woodford 2003: 84-85).

In this framework, out of equilibrium, that is when the market rate of interest is not equal to the snatural rate`, there is a difference between desired investment and desired savings. But the levels of investment and savings which actually occur are equal to the level of desired investment. When the actual rate of interest is above (below) the snatural rater, it is expected that desired investment is less (more) than desired saving. So even when desired saving is less than desired investment, the desired level of investment occurs, and in effect there is forced saving. Contrary to the argument that out of equilibrium the short side of 
the market dominates (Clower 1965) in this case investment is treated as dominating. In one sense this can be readily explained: investment expenditure is financed through bank loans, and provided banks are willing to supply the necessary loans at the prevailing rate of interest, the investment expenditure can take place. The role of banks is then central here, in responding to the assumed higher demand for loans in order to finance the investment expenditure. In terms of the discussion here, there are two points to note. First, it runs counter to loanable funds notions, and also counter to the argument frequently advanced in the financial repression literature that an interest rate below equilibrium would lead to low savings and thereby low investment. In this approach, a higher interest rate designed to lower inflation or prices would lead to lower investment, and thereby to lower capital formation. In the example discussed below this would imply that the reduction in inflation comes at a significant cost in terms of lost investment and hence productive capacity. Second, corresponding to (say) an excess of desired investment over desired saving, output and employment will be above their equilibrium levels (that is those corresponding to desired investment equal to desired saving). A mechanism by which this leads to higher inflation would be the Phillips' curve - a higher level of economic activity leading to a higher rate of inflation. We cast doubt on this link in Section 4.

Wicksell presented his argument for lower interest rates to lead to higher prices through the following example. Suppose banks lower their interest rate from four per cent to three per cent: then the market value of property based on discounted future rents (with an assumed infinite life) rises by 33 per cent. Investment in new property becomes profitable.

"Through competition in the building business materials, wages, the value of land and the price of building materials will therefore rise - in extreme cases this increase in prices might amount to as much as 33 per cent - and indirectly, the prices of all commodities that are consumed by workers, landowners and producers of materials will rise to some extent, through the increase in their demand. The most important thing, however, is that this rise in prices, be it large or small, cannot cease at this first stage, but must constantly be repeated as long as the low rate of interest continues. Once a general increase in prices has taken place, an economic equilibrium will soon be established again on the basis of this higher level of prices, and banks will now be able to return to their original rate of interest without thereby causing prices to return to their previous level.«(Wicksell 1958: 79).

A change in interest rate is intended, by definition, to impact on the interest-sensitive components of demand. Given the assumption which is made on a supply-side equilibrium (,full employment ), the question arises as to why a decrease (say) in the interest rate stimulates a general rise in prices rather than a rise in the relative price of interest-sensitive goods (and hence a fall in the relative price of other goods). For example, with $p_{C}$ price of consumption goods $(C), p_{I}$ price of investment goods $(I)$, by definition:

$$
p_{C} C\left(\frac{p_{C}}{w}\right)+p_{I} I\left(\frac{p_{I}}{p_{C}}, r\right)=\left[a p_{C}+(1-a) p_{I}\right] Q
$$


where $Q$ is a measure of total output. The inverse of the real wage, $p_{C} / w$ is treated here as given and derived from equality between the supply of labour as a function of $p_{C} / w$ and the labour required to produce $Q$. Full employment output $Q^{*}$ with given $p_{C} / w$ would generate an equation of the form:

$$
C\left(\frac{p_{C}}{w}\right)+\frac{p_{I}}{p_{C}} I\left(\frac{p_{I}}{p_{C}}, r\right)=\left[a+(1-a) \frac{p_{I}}{p_{C}}\right] Q^{*}
$$

which is an equation in $p_{I} / p_{C}$ and $r$. For a given $r$, there is then an equilibrium $p_{I} / p_{C}$. A lower $r$ (raising demand for $I$ ) would lead to a higher $p_{I} / p_{C}$, and hence higher price level $\left(a+(1-a) p_{I} / p_{C}\right)$ measured in consumption good terms (and since we treat $p_{C} / w$ as a given, prices higher relative to $w$ ).

This line of argument would suggest that the effects of variations in the policy interest rate would be on asset prices rather than output prices, with significant implications insofar as the changes in asset prices may develop into a bubble. It is also suggested that interest rate changes could have an effect on relative prices rather than the absolute level of prices.

For the moment we accept that a higher interest rate in a particular period would lead to lower prices in that period, and then ask the question, can that lead to lower inflation? In order to track through how the interest rate could influence the rate of inflation, we construct a simple example. Suppose that there is an on-going inflation of $\pi$ with actual inflation and expected inflation rates equal. The nominal rate of interest has been at $r$ and if that is maintained it is assumed inflation will continue at its current rate. Hence the real rate of interest $r-\pi$ is consistent with a constant rate of inflation, and with the actual price level turning out as expected. The benchmark case is given as scenario I in Table I.

\begin{tabular}{|c|c|c|c|c|c|}
\hline \multirow[t]{2}{*}{ Scenario } & \multirow[t]{2}{*}{ Variable } & \multicolumn{4}{|c|}{ Period } \\
\hline & & 1 & 2 & 3 & 4 \\
\hline \multirow{5}{*}{1} & nominal interest rate & $r$ & $r$ & $r$ & $r$ \\
\hline & price level & $P_{0}$ & $P_{0}(1+\pi)$ & $P_{0}(1+\pi)^{2}$ & $P_{0}(1+\pi)^{3}$ \\
\hline & rate of inflation & $\pi$ & $\pi$ & $\pi$ & $\pi$ \\
\hline & expected rate of inflation & $\pi$ & $\pi$ & $\pi$ & $\pi$ \\
\hline & real rate of interest & $r-\pi$ & $r-\pi$ & $r-\pi$ & $r-\pi$ \\
\hline \multirow{5}{*}{2} & nominal interest rate & $r$ & $r$ & $r+\Delta r$ & $r$ \\
\hline & price level & $P_{0}$ & $P_{0}(1+\pi)$ & $P_{0}(1+\pi)(1+\rho)$ & $P_{0}(1+\pi)^{2}(1+\rho)$ \\
\hline & rate of inflation & $\pi$ & $\pi$ & $\rho$ & $\pi$ \\
\hline & expected rate of inflation & $\pi$ & $\pi$ & $\pi$ & $\pi$ \\
\hline & real rate of interest & $r-\pi$ & $r-\pi$ & $r+\Delta r-\pi$ & $r-\pi$ \\
\hline
\end{tabular}




\begin{tabular}{|c|c|c|c|c|c|}
\hline \multirow[t]{2}{*}{ Scenario } & \multirow[t]{2}{*}{ Variable } & \multicolumn{4}{|c|}{ Period } \\
\hline & & 1 & 2 & 3 & 4 \\
\hline \multirow{5}{*}{3} & nominal interest rate & $r$ & $r$ & $r+\Delta r$ & $r+\Delta r$ \\
\hline & price level & $P_{0}$ & $P_{0}(1+\pi)$ & $P_{0}(1+\pi)(1+\rho)$ & $P_{0}(1+\pi)(1+\rho)^{2}$ \\
\hline & rate of inflation & & $\pi$ & $\rho$ & $\rho$ \\
\hline & expected rate of inflation & & $\pi$ & $\pi$ & $\pi$ \\
\hline & real rate of interest & & $r-\pi$ & $r+\Delta r-\pi$ & $r+\Delta r-\pi$ \\
\hline \multirow{5}{*}{$3^{\prime}$} & nominal interest rate & $r$ & $r$ & $r+\Delta r$ & $r+\Delta r$ \\
\hline & price level & $P_{0}$ & $P_{0}(1+\pi)$ & $P_{0}(1+\pi)(1+\rho)$ & $P_{0}(1+\pi)(1+\rho)(1+\mu)$ \\
\hline & rate of inflation & & $\pi$ & $\rho$ & $\mu$ \\
\hline & expected rate of inflation & & $\pi$ & $\pi$ & $\rho$ \\
\hline & real rate of interest & & $r-\pi$ & $r+\Delta r-\pi$ & $r+\Delta r-\rho$ \\
\hline \multirow{5}{*}{4} & nominal interest rate & $r$ & $r$ & $r+\Delta r$ & $r+\Delta r+\rho-\pi$ \\
\hline & price level & $P_{0}$ & $P_{0}(1+\pi)$ & $P_{0}(1+\pi)(1+\rho)$ & $P_{0}(1+\rho)^{3}$ \\
\hline & rate of inflation & & $\pi$ & $\rho$ & $\begin{array}{l}\left\{(1+\rho)^{2}-(1+\pi)\right\} /(1-\pi) \\
\text { (approximated by } 2 \rho-\pi)\end{array}$ \\
\hline & expected rate of inflation & & $\pi$ & $\pi$ & $\rho$ \\
\hline & real rate of interest & & $r-\pi$ & $r+\Delta r-\pi$ & $r+\Delta r-\pi$ \\
\hline
\end{tabular}

Now compare that with a higher rate of interest $r+\Delta r$ in period 3 and the price level is then lower than it would have been, and the price level is as indicated in the table and the rate of inflation in period 3 is $\rho$ (lower than $\pi$ ): this is scenario 2. Now if in period 4 interest rate is restored to $r$, with unchanged inflation expectations the price level is maintained at the expected level so that the expected price level is $P_{0}(1+\pi)^{2}(1+\rho)$, and the rate of inflation is back at $\pi$.

In scenario 3 , the interest rate is maintained at $r+\Delta r$; following the previous argument the price level in period 4 will be lower (to the extent of $(1+\rho) /(1+\pi)$ ) than otherwise - but what is the appropriate benchmark? One would be that the expectations of inflation remain at $\pi$ and hence that prices would have risen by $(1+\pi)$ if the rate of interest had been $r$, and hence the effects of an interest rate $r+\Delta r$ leads to a price level of $P_{0}(1+\pi)(1+\rho)(1+\pi)(1+\rho) /(1+\pi)=P_{0}(1+\pi)(1+\rho)^{2}$, and hence a rate of inflation of $\rho$. The continuation of this argument would imply that whilst the expected rate of inflation remains at $\pi$ and the rate of interest at $r+\Delta r$, the rate of inflation could be maintained at the lower rate of $\rho$. A higher rate of interest maintains a lower rate of inflation, but the rate of interest has to be maintained at that higher level indefinitely. However, it would be argued that the expectations of inflation adjust to the experience of inflation and hence the expected rate of inflation should be taken as $\rho$. This is scenario $3^{\prime}$ in Table I. This would 
mean that the benchmark price level in period 4 would be $P_{0}(1+\pi)(1+\rho)^{2}$, and the effect of the higher interest rate $r+\Delta r$ is taken to be a price level of $P_{0}(1+\pi)(1+\rho)(1+\mu)$ where $\mu<\rho$. As expectations have changed, the real rate of interest has risen further from $r+\Delta r-\pi$ to $r+\Delta r-\rho$ and the further reduction in inflation could be ascribed to a yet higher real rate of interest. If, in contrast, the nominal rate of interest were adjusted to take account of the change in expectations in order to maintain the real rate of interest (in this example at a real rate of $r+\Delta r-\pi$, which would mean a nominal rate of $r+\Delta r+\rho-\pi$ ), then the rate of inflation would continue at $\rho$.

In scenario 4 , the expected rate of inflation declines in period 4 , and the nominal rate of interest is adjusted so as to maintain a constant real rate of interest. This real rate of interest is such that it leads to a reduction in the price level below what it would have otherwise been (as above), and this leads to a further reduction in the rate of inflation to approximately $2 \rho-\pi$. Hence holding the real rate at $r+\Delta r-\pi$ continues to bring down the rate of inflation as long as expectations of inflation change in light of actual experience. This process could continue until the intended rate of inflation is reached. At that point, the real rate of interest can be lowered to $r-\pi$, which would imply a nominal interest rate of $r+\mu-\pi$ where $\mu$ is the target rate of inflation. By assumption here a real rate of interest equal to $r-\pi$ is consistent with an achieved price level in any particular period equal to the anticipated price level, which here implies a constant rate of inflation equal to $\mu$.

Scenario 2 is akin to the simulations often undertaken (e.g. by Bank of England 2005) of changing the interest rate for a specific period (e.g. year) and then returning it to the initial level. Typically in such models inflationary expectations are locked onto the target rate of inflation and the effect of a changed interest rate is on the price level rather than the rate of inflation - there is a difference between output and what it would have been which is gained or lost forever.

Now consider the case where inflation is already at its target level $\left(\pi_{T}\right)$, and expectations of inflation are set accordingly. But suppose that there is a >blip in inflation in the sense that in a given period it rises above the target level through a rise in costs (`supply-side shock ) or through higher demand (>demand-side shocks) which is not related to the interest rate (e.g. a boost in foreign demand). In effect this is the way in which changes in inflation are represented in the NCM with there being an explicit random term in the equation for inflation representing supply-side shocks, while demand shocks operate via the random term in the 'IS < equation, and then through the effect of demand in the inflation equation. If the sblip is random, is there any purpose served by raising the interest rate in response to it as over time the `blips a average out? There are two possible arguments for doing so. First, if the variability of inflation (rather than the level) is an issue, then seeking to offset the sblips could reduce the variability, but there are some obvious problems here akin to those relating to attempts at fine tuning. The random shocks have to be observed and recognised, and then appropriate policy measures taken where the effects of such a measure is often viewed as uncertain and coming through with a considerable lag. Second, there can be sspill-over effects from the sblips: if, for example, what would otherwise be a temporary rise in inflation leads peo- 
ple to revise their expectations of future inflation, then the rise in inflation could persist. An increase in interest rates may then be taken as a signal that the Central Bank is son the caser, and expectations on inflation are constrained. "Not only do expectations about policy matter, but, at least under current conditions, very little else matters. (Woodford 2003: I5). A case which rather falls outside the NCM would be where inflation involves some change in relative prices - this may be the relationship between wages and prices, between costs and prices, or between prices of products. The groups which have lost out through the change in relative prices may seek to restore their position which would mean raising their prices, e.g. workers raising wages in response to an increase in output prices.

Our conclusion from this discussion is that with a given set of expectations of future inflation, a change in the rate of interest would lead to a change in the price level, and that a reduction in inflation (resulting from the higher interest rate) would either require that the interest rate is maintained at a higher level indefinitely or that the expectations of inflation change as a result of experience.

\section{Asset prices, exchange rates and inflation}

In the schema presented by the Bank of England (1999) (and in effect presented elsewhere, for example, European Central Bank 2004, Chart 3.I) there are four routes through which the policy rate of interest is said to have an impact on inflation, namely through market rates of interest, asset prices, exchange rate and sonfidencer. The exchange rate has an impact on the level of demand through impact on import and export demand, and the exchange rate also has an effect on import prices. It should be mentioned as an aside here that each of the links between interest rate and inflation may be rather weak and subject to uncertainty, but that issue lies outside the scope of this paper. The approach here is to briefly discuss these channels in turn so that we can examine whether the linkage between the level of the rate of interest and the rate of inflation (as opposed to the price level) is warranted.

The line of argument concerning asset prices and the level of demand is straightforward: a lower interest rate leads to a higher (discounted) value of assets, thereby generating a wealth effect, with subsequent effects on the level of demand. The wealth effect (as compared with some base case) will remain so long as the interest rate remains low. At this stage there is a level to level effect - that is the level of interest rates influences the level of asset prices, which in turn influences the level of demand. The translation into a rate of change would have to come as the level of demand impacts on the rate of inflation, a translation to which we return below.

In the theoretical literature on the NCM little attention is paid to the exchange rate for the obvious reason that the analysis relates to a closed economy. Yet empirical evidence (e.g. Church et al. I997, House of Lords 1999) suggests that a considerable proportion (that is more than half) of any effects of interest rates on inflation comes through the exchange rate, and as can be seen from above, the exchange rate channel features in the Bank of England schema in two ways, in terms of the effect on demand and the effect on import prices. 
There are though two questions to be addressed here. First, what is the anticipated effect of say a higher interest rate on the exchange rate; and second, does a higher exchange rate lead to a change in the price level and/or to a change in the rate of inflation?

There are (at least) two rather different perspectives on the links between interest rates and exchange rates. The first is that a higher interest rate (particularly if unexpected) would tend to lead to a higher exchange rate (as capital funds flow towards the higher interest rate). The higher exchange rate tends to lead to lower import prices though there is a question of how substantial the pass through will be. But the linkage is from a change in the interest rate, to a change in the exchange rate, to a change in import prices. If (say) a higher interest rate is maintained, this may help to maintain the higher exchange rate but there would seem no reason for the exchange rate to continue to rise and hence, for import prices to decline. The effect of a higher interest rate on prices is one-off.

The second linkage comes from forms of interest rate parity whereby the interest rate differential (between two currencies) is in line with the rate of change of the exchange rate. Specifically a higher domestic interest rate would be associated with a depreciating exchange rate, and hence a continually rising price of imports. The interest rate parity approach is an arbitrage condition, and the mechanism through which the relationship is brought about is not specified. In the context of our argument here, the significant element is the association of a higher interest rate with a higher rate of inflation.

The significance of these arguments is that an effect of the interest rate running through the exchange rate could well be a one-off, that is a higher interest rate raises the exchange rate, which may lower import prices, but maintaining a higher interest rate would not have any continuing effect on the exchange rate and thereby on price changes.

\section{The level of demand and the rate of inflation (a.k.a. the Phillips' curve)}

A link from the level of demand to the rate of inflation is a vital one in the chain from interest rate to inflation. Some form of Phillips' curve is invoked where we use the term Phillips' curve to cover those approaches which see the rate of inflation as related to the expected rate of inflation and some measure of economic activity. As an aside we could also note that this Phillips' curve notion is an important ingredient in the arguments for taking interest rate decisions out of the hands of politicians who were perceived as tempted to stimulate demand with consequent higher inflation.

In Sawyer (20IO), the argument is developed at length that there is no strong theoretical link running from the level of demand to the rate of inflation (see also Arestis/Sawyer, 2008 b). Specifically each of the variety of ways in which attempts have been made to provide theoretical links are discussed and found wanting. There is not space here to develop those arguments, but we can summarise the essence of the argument. In microeconomic analysis, the level of prices (relative to costs) can be viewed as related to the level of demand and the level of output. The relationship can be a positive or negative one, and indeed some would argue that prices relative to costs are close to invariant with respect to output. Inso- 
far as there is a relationship it is one of the level of prices with the level of output. In contrast, the Phillips' curve postulates that the rate of change of prices is related to the level of economic activity. Indeed, it can be taken further, in that when expectational variables are included, it is something approaching the second derivative of prices (actual inflation minus expected inflation), which is related to the level of economic activity.

From any model of price determination it is possible to derive a relationship between the desired price (to be charged by the firm) and unit costs. Let us write this as $p=f(c, q)$ where $p$ is $\log$ of the price level, $c$ is an appropriate index of costs and $q$ is $\log$ of output. If this relationship is treated as holding instantaneously, then by differentiation with respect to time then the rate of price change would be $\pi=f_{1}(c, q) \dot{c}+f_{2}(c, q) \dot{q}$ which clearly does not correspond to any notion of the Phillips' curve given the significant role of change in output. Alternatively $p^{*}=f(c, q)$ may be treated as the desired price $p^{*}$ to which an adjustment process can be added and hence $\pi=f_{1}(c, q) \dot{c}+f_{2}(c, q) \dot{q}+\chi[f(c, q(t))-p(t)]$ where the last term represents the adjustment of actual price towards the desired price. There is a clear conflict with any Phillips' curve notions based on price change being linked with the level of economic activity alone. Clearly we could move in the reverse direction, namely start from an equation, which relates inflation with the level of economic activity, and integrate over time to reach an equation that relates the price level to the cumulative level of economic activity since time began.

A similar argument can be applied in the case of wage formation. Models of wage determination including efficiency wages often postulate that the level of real wages will be related to the level of employment (or unemployment). Empirically this could be viewed as encapsulated in the rwage curver (e.g. Blanchflower/Oswald 1994) in which the level of real wages is related to the level of unemployment. It is again clear that there is a conflict between the notion that the level of real wages is related to the level of unemployment and the Phillips' curve notion that the rate of change of wages (whether nominal or expected real wages) is set by the level of unemployment.

Our conclusion is then that the link between the level of economic activity and the rate of inflation is not well-founded. Since the level of interest rates is taken to influence the level of economic activity, this conclusion further undermines any link between the level of interest rates and the rate of inflation.

\section{Interest rates and inflation: Empirics}

In Bank of England (2005), Figure 4.I indicates that the effect of a one per cent increase in nominal interest rates held for a year (and then with interest rate policy following a simple Taylor rule) on inflation would be a maximum decline in inflation of 0.3 per cent. This result is in line with other findings, which we have surveyed in Arestis/Sawyer (2004). We concluded there that 
"First, (at least within the context of the macroeconometric models) there are constraints to a permanent change in the rate of interest. We would see the effect of interest rate on the exchange rate (when interest rate parity is assumed) as being a significant element in this (in that an interest differential between the domestic interest rate and foreign interest rate leads to a continual change in the exchange rate). Second, and this is clear in the case of the euro area models, when interest rates have an effect on aggregate demand this comes through from substantial changes in the rate of investment [...]. This means that interest rate variations can have long lasting effects, in that the effects on investment will lead to changes in the size of the capital stock. Third, the effects of interest rate changes on the rate of inflation are rather modest $[\ldots]$. A one percentage point change in interest rates is predicted to lead to a cumulative fall in the price level of $0.4 \mathrm{I}$ per cent in one case and 0.76 per cent in the other, after five years. The rate of inflation declines by a maximum of 0.21 percentage points." (Arestis/Sawyer 2004: 26-27).

The conclusion that the effect of interest rate changes on inflation is small may be modified by the reflection that

"The simulation shown in Figure 4.I is based on the assumption that the unexpected change in interest rates does not affect agents' long-run inflation expectations. But the response of the economy to a change in interest rates depends on the credibility of the inflation target. In particular, as inflation expectations become more firmly anchored around the inflation target - the target becomes more credible - a change in the short-term interest rate is likely to have less impact." (Bank of England 2005: 13I).

\section{Concluding remarks}

The purpose of this paper has been to examine some of the links in the chain which is said to run from the rate of interest to the rate of inflation. It has been suggested that there is a tendency to slip from arguments in which the rate of interest is related to the price level, to suggesting that the rate of interest is related to the rate of inflation. We have pointed to a problem in establishing that the level of demand is relevant for the rate of inflation. We have likewise suggested that the route through the exchange rate does not support the view that a higher interest rate will dampen down inflation (though it may lower prices relative to what they would have been). In the last section we have rather briefly indicated the lack of empirical support for any strong link from interest rates to inflation.

A central element in an inflation targeting regime is the use of the policy rate of interest to target the rate of inflation through the effects of the rate of interest on demand and of demand on inflation. If that linkage does not operate or operates weakly, then inflation targeting is fatally undermined. All that would be left would be an sindependent Central 
Bank which adjusts the policy interest rate, not to influence inflation directly, but to confirm low inflationary expectations through appearing to do something, even if that something has little effect. In this paper we have cast doubt on the nature and strength of links from the policy interest rate to the rate of inflation. This then opens up the way to explore two major avenues. First, what should interest rate policy be doing? In another paper (Sawyer 2009) it has been argued that interest rate policy should be geared to attaining a real rate of interest in line with the underlying rate of growth of the economy, and that any attempt at fine-tuning through variation in the policy rate of interest should be abandoned. Second, if the policy rate of interest is ineffectual in targeting inflation, then the search has to be resumed for a socially acceptable alternative.

\section{References}

Arestis, P., Sawyer, M. (2004): Can monetary policy affect the real economy?, in: European Review of Economics and Finance, 3, 9-32.

Arestis, P., Sawyer, M. (2008a): A critical reconsideration of the foundations of monetary policy in the new consensus macroeconomics framework, in: Cambridge Journal of Economics, 32, 76I - 779.

Arestis, P., Sawyer, M. (2008b): The weak foundations of the Phillips' curve, University of Leeds, mimeo.

Bank of England (1999): The Transmission Mechanism of Monetary Policy, London: Bank of England.

Bank of England (2005): The Bank of England Quarterly Model, London: Bank of England.

Blanchflower, D.G., Oswald, A.J. (1994): The Wage Curve, Cambridge, Mass.: M.I.T. Press.

Church, K.B., Mitchel, P.R., Sault, J.E. and Wallis, K.F. (1997): Comparative performance of models of the UK economy, in: National Institute Economic Review, I6I, 9I - Ioo.

Clower, R.W. (1965): The Keynesian counter-revolution: A theoretical appraisal, in: Hahn, F., Brechling, F. (eds.), The Theory of Interest Rates, London: Macmillan, I03 - I25.

European Central Bank (2004): The Monetary Policy of the ECB, Frankfurt: European Central Bank.

House of Lords (1999): Monetary Policy Committee of the Bank of England - Report (No. HL 96). London: House of Lords Select Committee on the Monetary Policy Committee of the Bank of England.

Leith, S., Wren-Lewis, S. (2005): Fiscal stabilization policy and fiscal institutions, in: Oxford Review of Economic Policy, 21, 584- 597.

Meyer, L.H. (200I): Does money matter?, in: Federal Reserve Bank of St. Louis Review, 83, I -15 .

Sargent, T.J., Wallace, N. (1975): `Rationak expectations, the optimal monetary instrument, and the optimal money supply rule, in: The Journal of Political Economy, 83, 24I - 254.

Sawyer, M. (2009): Towards a new framework for fiscal and interest rate policy, in: Journal of Post Keynesian Economics, forthcoming. 
Sawyer, M. (2010): The Political Economy of the Phillips' Curve, Aldershot: Edward Elgar, forthcoming.

Taylor, J.B. (2000): Reassessing discretionary fiscal policy, in: Journal of Economic Perspectives, I4, $2 \mathrm{I}-36$

Wicksell, K. (1958): Selected Papers on Economic Theory (edited with an introduction by Erik Lindahl), London: George Allen \& Unwin.

Woodford, M. (2003): Interest and Prices: Foundations of a Theory of Monetary Policy, Princeton: Princeton University Press. 